\title{
Monostotik mandibular fibröz displazi: Olgu sunumu
}

\author{
Ahmet Taylan Çebi(0000-0001-9083-7215) ${ }^{\alpha}$, Kadri İla(0000-0003-3211-6107) ${ }^{\beta}$, Nihat Yılmaz(0000-0003-1575-1280 ${ }^{\gamma}$ \\ Selcuk Dent J, 2019; 6: 57-60 (Doi: 10.15311/selcukdentj.348767) \\ Başvuru Tarihi: 01 Kasım 2017 \\ Yayına Kabul Tarihi: 20 Mart 2018
}

\begin{abstract}
Öz
Monostotik mandibular fibröz displazi: Olgu sunumu

Fibröz displazi sıklıkla çocuk yaşlarda ve ergenlerde görülen kemiğin gelişimsel, yavaş büyüyen, fibroosseöz benign bir lezyonudur. Fibröz displazi bir ya da birden çok kemiği etkiliyebilir. Fibröz displazi klinik olarak ikiye ayrilır ve bunlar monostotik ve poliostotik fibröz displazi olarak adlandırılırlar. Radyografik görüntüsünde, displazik lezyon içindeki artan kemik oluşumunda birlikte 'buzlu cam' veya 'portakal kabuğu' görüntüsünü andırmaktadır. $\mathrm{Bu}$ olgu sunumunda klinik, radyografik ve histopatolojik incelemelerle tanısı koyulmuş fibröz displazi olgusu sunulmuştur.
\end{abstract}

\section{ANAHTAR KELIMELER}

Fibröz displazi, mandibula, monostotik, poliostotik

Fibröz displazi (FD), kemiğin yapısal olarak daha zayıf fibröz ve osseöz doku ile yer değiştirmesi sonucu oluşan, lokalize, gelişimsel, benign bir kemik hastalığı olmakla beraber çok nadir de olsa malign dönüşüm gösterebilen bir kemik hastalığıdır. ${ }^{1}$ Normal kemikle yer değiştiren fibröz bağ dokusunun içinde kemik trabekülleri bulunmaktadır. ${ }^{2}$ Fibröz displazinin maksillofasiyal bölgede bulunması, çene ve yüz kemiklerinde deformite ve asimetriye neden olduğu için hem fonskiyonel hem estetik hem de kozmetik anlamda önem taşımaktadır. Fibröz displazi, asemptomatik olarak büyüyen kemik ekspansiyonları ile karakterizedir. Lezyonlar büyük boyutlara ulaştıklarında estetik, fonksiyon kaybına ve bozukluğuna ayrıca çene kemiklerini tuttuklarında ise dişlerin migrasyonuyla oklüzyon bozukluklarına neden olabilir. Ayrıca kafa kemiklerindeki tutum alanlarına ve tipine göre işitme kaybı, parestezi, ağrı, görme bozuklukları ve nasal obstrüksiyon yapabilirler. ${ }^{3}$

Fibröz displazi, monostotik fibröz displazi ve poliostotik fibröz displazi olmak üzere temel olarak klinikte 2'ye ayrılmaktadır. Monostotoik fibröz displazi tek bir kemiği tutar ve en hafif olarak seyreden ve en sık görülen formdur. Poliostotik form ise birden fazla sayıda kemiği tutan ve monostotik forma göre daha

\begin{abstract}
Surgical treatment of salivary gland stones: Two case reports

Fibrous dysplasia is a formative, slow growing, benign fibrousosseous lesion of the bone and is for the most part found in in children and adolescents. Fibrous dysplasia may effect one or more bones. Fibrous dysplasia has two clinical structures; monostotic and polyostotic. Increases in bone arrangement inside the lesion make a radiographic appearance that is alluded to as 'ground glass' or 'orange peel'. In this report, fibrous dysplasia, whose finding are made with clinical, radiographic and histopathological, are presented.
\end{abstract}

\section{KEYWORDS}

Fibrous dysplasia, mandible, monostotic, polyostotic

daha nadir görülen tiptir. Monostotoik fibröz displazi genel olguların \%70'ini oluştururken, poliostotik fibröz displazi ise \%30 kadarını oluşturmaktadır. Poliostotik fibröz displazi kendi içersinde; Jaffe tipi fibröz displazi ve McCune Albright Sendromu olarak iki alt grupta değerlendirilmektedir. Jaffe tipi fibröz displazide çok sayıda kemik tutulumu mevcuttur ve deride 'sütlü kahve lekeleri' adı verilen pigmente yapılar bulunmaktadır. McCune Albright Sendromu ise deri pigmentasyonlarınında bulunduğu, neredeyse bütün vücut kemiklerini tutan ciddi bir endokrin bozuklukluğudur. ${ }^{4}$

Fibröz displazi tüm kemik tümörlerinin \%3'ünü oluştururken iyi huylu kemik tümörlerinin ise \%7'sini oluşturmaktadır. $^{5}$ Fibröz displaziden en fazla etkilenen kemikler kafa kemikleridir. Çene kemikleri arasında ise maksillada mandibulaya oranla daha fazla görülmektedir. ${ }^{6}$ Fibröz displazinin teşhisinde konvansiyonel röntgenler, bilgisayarlı tomografi (BT), sintigrafi ve histopatoloji kullanılabilir. Fibröz displazinin radyografik bulguları patolojinin maturasyon düzeyine göre değişiklik göstermektedir. Radyografide fibröz displazi kendisini tipik olarak 'buzlu cam' ya da 'portakal kabuğu' şeklinde belli etmektedir. ${ }^{4,7,8}$

\footnotetext{
${ }^{\alpha}$ Karabük Üniversitesi Diş Hekimliği Fakültesi Ağız, Diş ve Çene Cerrahisi Anabilim Dalı, Karabük, Türkiye

${ }^{\beta}$ Karabük Üniversitesi Tıp Fakültesi Kulak, Burun ve Boğaz Hastalıkları Anabilim Dalı, Karabük, Türkiye

${ }^{\gamma}$ Karabük Üniversitesi Tıp Fakültesi Kulak, Burun ve Boğaz Hastalıkları Anabilim Dalı, Karabük, Türkiye
} 
Fibröz displazi olgularında tedavi seçenekleri olarak herhangi bir cerrahi müdahale edilmeden, bir işlem yapılmadan hasta takibi ve gözlem yapılabileceği gibi medikal tedavi (bifosfonat ilaç tedavisi), konservatif ya da radikal cerrahi ve rekonstrüksiyon sayılabilir. Cerrahi tedavideki amaç; oluşabilecek patolojik fraktürleri engellemek, mevcut olan ağrıyı gidermek ve kemikteki mevcut deformiteleri azaltmaktır.6 Bu makalede yalnızca mandibulada bulunan, klinik, radyolojik ve histopatolojik değerlendirmeler yapıldıktan sonra monostotik fibröz displazi tanısı konulan bir olgunun sunumu amaçlanmıştır.

\section{OLGU SUNUMU}

20 yaşında erkek hasta, Karabük Üniversitesi Diş Hekimliği Fakültesi Ağız Diş ve Çene Cerrahisi kliniğine alt çenede şişlik şikayetiyle başvurdu. Hastanın alınan anamnezinde alt çenesinde meydana gelen şişliğin yaklaşık 5 aydır bulunduğu ve giderek boyutunun arttığı öğrenildi. Herhangi bir sistemik hastalığı bulunmayan hastanın intraoral muayenesinde herhangi bir ekspansif alan bulunmazken, ekstraoral muayenesinde ise sol mandibula corpus ve angulus bölgesinde vestibüle ve mandibular border sınırına doğru ekspansiyon gösteren ağrısız, sert, kemik benzeri bir çıkıntı gözlendi (Resim 1). Hastadan çekilen panoramik radyografide; kemikte sol mandibular corpus ve angulus kısmında kemik hacminin daha fazla olduğu ve fibröz displazinin karakteristik bulgusu olan 'buzlu cam' görüntüsü saptandı (Resim 2). Daha detaylı bir inceleme yapabilmek için bilgisayarlı tomografi alındı. Bilgisayarı tomografide mandibula sol kısımda yaklaşık $3.5 \mathrm{x}$ $2 \mathrm{~cm}$ boyutlarında kemikte ekspansiyona neden olan ancak kortekste erozyon veya dekstrüksiyona neden olmayan fibröz displaziyle uyumlu lezyon gözlemlendi (Resim 3). Yapılan klinik muayene ve radyografik incelemeler neticesinde monostotik fibröz displazi tablosunu düşündüren lezyondan biyopsi yapılmasına karar verildi. Lokal anestezi altında intraoral olarak lezyonun vestibüle doğru ekspansiyon yapan kısmından punch biyopsisi yapıldı. Mandibula dış kısmında kemik kontür düzeltmesi yapılarak hastanın şikayetçi olduğu kozmetik problem ortadan kaldırıldı. Histopatolojik incelemede kesitlerde sellüler fibroblastik stroma içerisinde lameller kemik dokusu izlendi. Klinik, radyodiagnostik ve histopatolojik tanılar ön tanıyla uyumlu olarak bulundu. Hastanın 6 aylık takibinde herhangi bir kemik büyümesi ve ağrı, okluzyon bozukluğu gibi bir problemle karşılaşımadı. Hastanın takibine tarafımızca devam edilmektedir.

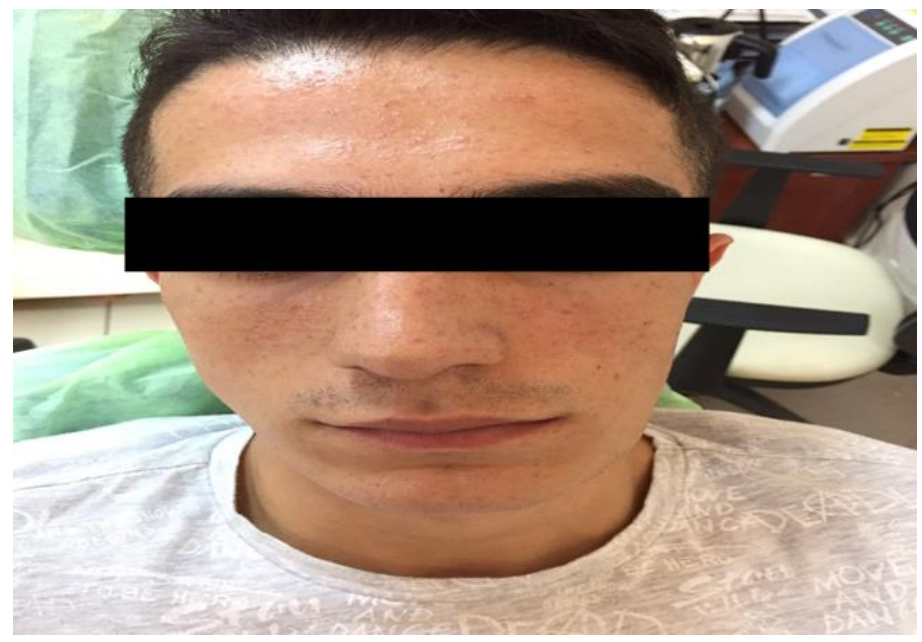

Resim 1.

Mandibula sol-posterior bölgede bulunan lezyonun ekstra-oral görüntüsü

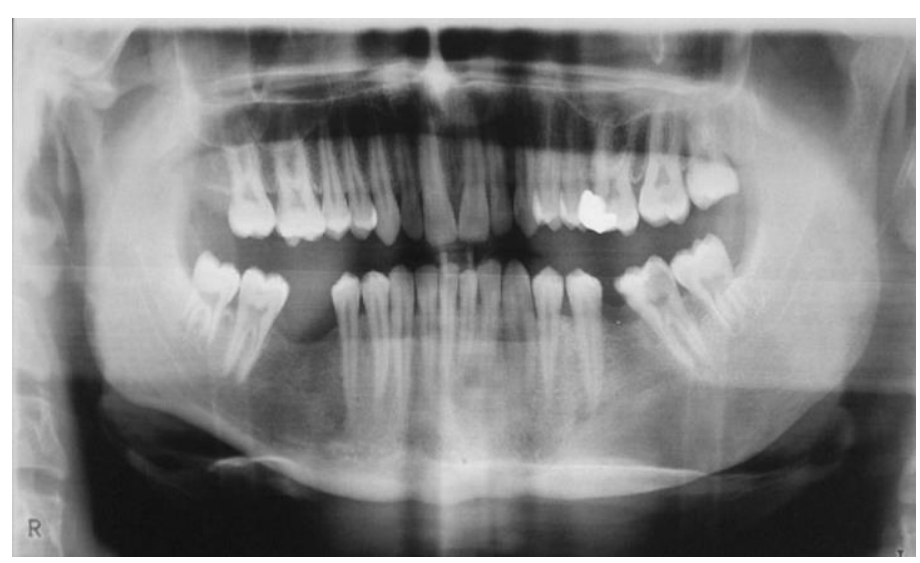

Resim 2.

Sol mandibuladaki lezyonun panoramik radyografi

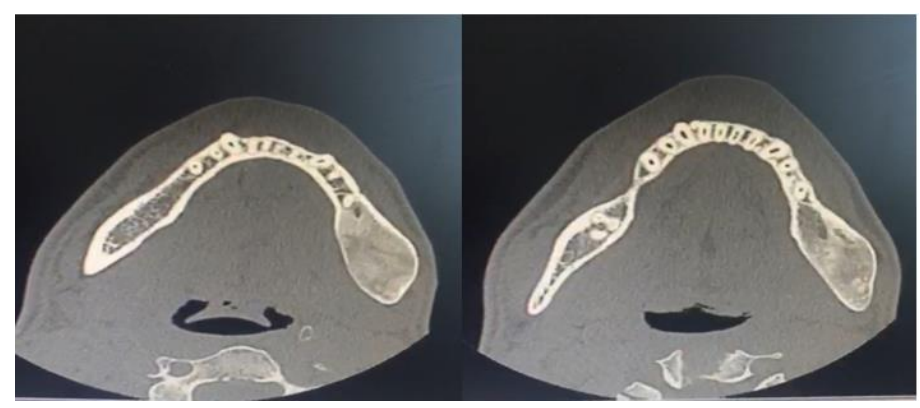

Resim 3.

Mandibula posteriror bölgede lokalize lezyonun aksiyal kesit bilgisayarlı tomografi görüntüsü

\section{TARTIŞMA}

Fibröz displaziler cinsiyet ayrımı yapmaksızın kadın ve erkeklerde eşit bir şekilde görülür..$^{6,8}$ Genellikle hayatın ilk üç dekatında görülür. Fibröz displazide kemik gelişimin olgunlaşması ve tamamlanmasıyla lezyonların stabil kalacağı düşünülmektedir. ${ }^{9}$ Bizim vakamızda da erkek hastanın yaşı 20 olup litaretürle uyumludur. 
Kafa kemikleri arasında en fazla tutulum gösteren kemikler; frontal kemik ve maksilladır. Fibröz displazi mandibulada maksillaya oranla daha nadir görülür. Lustig ve arkadaşları kafatası kemikleri içerisinde en fazla ethmoid kemikte tutulum olduğunu, diğer kemiklerde ise tutulum sıklığının sırasıyla sfenoid, frontal, maksilla, temporal, parietal ve oksipital kemikler olduğunu çalışmalarının sonucunda bildirmişlerdir. ${ }^{10}$ Sunduğumuz vakada ise fibröz displazi sol mandibular posterior bölgede bulunmaktadır.

Monostotik tip fibröz displazide lezyonlar sıklıkla tek tarafıdır. Fakat baş-boyun bölgesinde görülen geniş lezyonlarda çok nadir de olsa çift taraflı tutulum da olabilir. ${ }^{11}$ Bizim olgumuzda fibröz displazi mandibulada unilateral olarak izlenmiştir.

Fibröz displazide teşhis genellikle klinik muayene ve radyolojik görüntüleme yöntemleriyle konulabilir. Lezyon radyografide radyoopak, radyolüsent veya ikisinin karışımı (mikst) şeklinde görülebilir. İlk safhalarda genellikle lezyon radyolüsent oalrak görüntü verir. İlerleyen safhalarda ise trabeküler kemiğin incelmesi, kısalması ve düzensiz sınırlanması sonucu opasitenin artmasıly birlikte mikst ya da buzlu cam adı verilen dansitede kemikte ekspansiyon yapan bir görüntü verebilir. Fibröz displazinin ayrıcı tanısında; santral dev hücreli granülom, ossifying fibrom, ameloblastik fibrom ve ameloblastik fibroodontom ve osteosarkom gibi benzer radyografik görünüm sergileyen lezyonlara dikkat edilmelidir. ${ }^{12,13}$ Bizim sunduğumuz vakamızda da teşhisin konulmasında yapılan klinik muayene sonucunda elde edilen veriler ve radyografik muayene yardımcı olmuştur. Bilgisayarı tomografi yardımıyla fibröz displazik lezyonun sınırları tespit edilmiştir. Lezyondan alınan biyopsi sonucunda monostotik fibröz displazi tanısı doğrulanmıştır.

Maksilla ve mandibulada bulunan, asemptomatik olarak büyüme gösteren fibröz displazi olgularında, dişler gömülü kalabilirler, dişlerde meydana gelen migrasyon ile oklüzyonda bozukluk meydana gelebilir, mandibuladaki fibröz displazi lezyonları mandibular sinir kanalının yer değiştirmesine sebep olabilirken, maksillada bulunan fibröz displaziler ise maksiller sinüsü ve göz tabanını etkileyebilirler. ${ }^{14}$ Bizim vakamızda fibröz displazi lezyonları mandibula yerleşimli olup, ağrısız ekspansiyonlar mevcuttu.

Fibröz displazi tedavisi; hasta takibi, lezyonun radikal cerrahi ile çıkarıması, konservatif cerrahi ile kemik kontüründe düzeltme yapılması ve medikal tedavide kullanılan ilaçlar (antirezorptif ajanlar) ile yapılmaktadır. Estetik kayıp oluşturmayan küçük ve herhangi bir semptomu bulunmayan displazik lezyonların tedavisinde hasta takibi ve gözlem tercih edilen tedavi seçeneklerindendir. ${ }^{6}$ Medikal tedavide antirezorptif ilaçlar önerilmiştir fakat bu yöntem fibröz displazi lezyonlarının tedavisinde öncü bir rol oynamamaktadır. Kemikte yapısal bozukluğa, fonksiyon ve estetik kaybı gibi sonuçlara neden olan lezyonlar ise, kemikte yapılan kontür düzeltilmesi ile tedavi edilebilmektedir. ${ }^{15}$ Bizim hastamızda da vestibül ekspansiyon gösteren ve hastanın estetik olarak rahatsız olduğu bölgede kontur düzeltmesi yapılmış ve hasta takibe alınmıştır.

Sonuç olarak; genç yaşlarda daha fazla görülen fibröz displazinin malign bir lezyon olmadığı konusunda hastalar bilgilendirilmelidir. Nüks görülebilme intimali ve düşükte olsa varolan malign transformasyon riskinden dolayı hasta takipleri yapılmalıdır. Ayrıca fibröz displazinin etkili şekilde tedavi edilebilmesi içinde vakaya özel tedavi protokollerinin uygulanması gerektiğinin kanaatindeyiz. 


\section{KAYNAKLAR}

1. Mladina R, Manojlovic S, Glavas DM, Heinrich Z. Isolated unilateral fibrous dysplasia of the sphenoid sinus. Ann Otol Rhinol Laryngol 1999; 108(12): 1181-4.

2. Selçuk Ü, Muğlalı $M$, Çelenk $P$, Canger $M$, Günhan Ö. Monostatik fibröz displazi: Olgu sunumu. Journal of Experimental and Clinical Medicine 2013; 30, 9193.

3. Lee JS, FitzGibbon EJ, Chen YR, Kim HJ, Lustig LR, Akintoye SO, et al. Clinical guidelines for the management of craniofacial fibrous dysplasia. Orphanet J Rare Dis 2012; 7, 1-2.

4. Sontakke SA, Karjodkar FR, Umarji HR. Computed tomographic features of fibrous dysplasia of maxillofacial region. Imaging Sci Dent 2011; 41, 2328.

5. Bequignon E, Cardinne C, Lachiver X, Wagner I, Chabolle F, Baujat B. Craniofacial fibrous dysplasia surgery: a functional approach. Eur Ann Otorhinolaryngol Head Neck Dis 2013; 130, 215-20.

6. Menon S, Venkatswamy S, Ramu V, Banu K, Ehtaih S, Kashyap VM. Craniofacial fibrous dysplasia: Surgery and literature review. Ann Maxillofac Surg 2013; 3, 66-71.

7. MacDonald-Jankowski DS, Yeung R, Li TK, Lee KM. Computed tomography of fibrous dysplasia. Dentomaxillofac Radiol 2004; 33(2): 114-8.

8. Ricalde P, Horswell BB. Craniofacial fibrous dysplasia of the fronto-orbital region: a case series and literature review. J Oral Maxillofac Surg 2001; 59(2): 157-67

9. Rahman AM, Madge SN, Billing $\mathrm{K}$, Anderson PJ, Leibovitch I, Selva D, et al. Craniofacial fibrous dysplasia: clinical characteristics and longterm outcomes. Eye (Lond) 2009; 23, 2175-81.

10.Lustig LR, Holliday MJ, McCarthy EF, Nager GT. Fibrous dysplasia involving the skull base and temporal bone. Arch Otolaryngol Head Neck Surg 2001; 127, 1239-47.

11.Singer SR, Mupparapu M, Rinaggio J. Clinical and radiographic features of chronic monostotic fibrous dysplasia of the mandible. J Can Dent Assoc 2004; 70: 548-52.

12.Feller L, Wood NH, Khammissa RA, Lemmer J, Raubenheimer EJ. The nature of fibrous dysplasia. Head Face Med 2009; 5: 22.

13.Atalar M, Ozum U. Monostotic fibrous dysplasia of the clivus: imaging findings. Turkish Neurosurgery 2010; 20: 77-81.

14.Pruksakorn P, Shuangshoti S, Siwanuwatn R, Lerdlum S, Sunthornyothin S, Snabboon T. Craniofacial fibrous dysplasia. Intern Med 2010; 49, 24950.
15. Regezi JA, Sciubba JJ. Oral Pathology. Clinical pathologic correlations 3rd edn. W.B. Saunders Company, Philadelphia, Pennsylvania 1999; 360-3.

Yazışma Adresi:

Ahmet Taylan ÇEBi

Karabük Üniversitesi Diş Hekimliği Fakültesi

Ağız, Diş ve Çene Cerrahisi AD

Karabük

Tel : : +903704334401/1196

Faks : +90370 4330502

E-Mail : ahmettaylancebi@karabuk.edu.tr 